TITLE:

\title{
Digesta Passage Time, Digestibility, and Total Gut Fill in Captive Japanese Macaques (Macaca fuscata): Effects Food Type and Food Intake Level
}

\section{AUTHOR(S):}

Sawada, Akiko; Sakaguchi, Ei; Hanya, Goro

\section{CITATION:}

Sawada, Akiko ... [et al]. Digesta Passage Time, Digestibility, and Total Gut Fill in Captive Japanese Macaques (Macaca fuscata): Effects Food Type and Food Intake Level. International Journal of Primatology 2011, 32(2): 390-405

\section{ISSUE DATE:}

2011-04

URL:

http://hdl.handle.net/2433/139523

\section{RIGHT:}

The final publication is available at www.springerlink.com; この論文は 著者最終稿です。内容が印刷版と異なることがありますので、引用の 際には出版社版をご確認ご利用ください。This is the Accepted Author Manuscript. Please cite only the published version. 
1 Digesta passage time, digestibility and total gut fill in captive Japanese macaques: the effects of food type and food intake level

4 AKIKO SAWADA $^{1}$, EI SAKAGUCHI ${ }^{2}$ AND GORO HANYA ${ }^{1}$

$6 \quad{ }^{1}$ Primate Research Institute, Kyoto University

$7 \quad{ }^{2}$ Graduate School of Natural Science and Technology, Okayama University

13 "Correspondence to: Akiko SAWADA, Primate Research Institute, Kyoto

14 University, Inuyama, Aichi, 484-8506, Japan. Telephone: +81-568-63-0545,

15 facsimile: +81-568-63-0564, e-mail: a_sawada@pri.kyoto-u.ac.jp 


\section{Abstract}

Digestion is an important process in understanding the feeding ecology

of animals. We examined digesta passage time, digestibility, and total gut fill in Japanese macaques $(n=4)$ under four diet conditions representing the seasonal and regional variations in the diets of wild populations to determine the effects of food type and food intake on these digestive features. Food type was associated with mean retention time (MRT), digestibility, and total gut fill. Dry matter intake (DMI) of food was positively correlated with total gut fill but not with MRT or digestibility. Indigestible DMI, on the other hand, affected MRT negatively. Thus, when Japanese macaques consume high-fiber foods, MRT becomes shorter and digestibility is lower than eating low-fiber foods.

Moreover, macaques experience increases in total gut fill when they consume high-fiber diets or a large amount of food. Japanese macaques may excrete difficult-to-digest food components quickly: they nevertheless buffer an increase in food intake by an increase in gut fill. Our study offers new insight into the relationship between feeding ecology and nutritional physiology in primates by simultaneously examining the effects of food type and intake level on MRT and digestibility. 
38 Key words: digesta passage time; mean retention time; digestibility; total gut

39 fill; Macaca fuscata

40 


\section{Introduction}

Animals must absorb nutrients and energy from the foods they ingest

and digest (Robbins 1983). Since the amount of food they need to eat highly depends on how efficiently they can digest food, digestibility must be taken into account to understand energy balance. Plant foods are rich in hard-to-digest structural carbohydrates such as cellulose and hemicellulose. The relatively large and/or sometimes compartmentalized gastrointestinal tracts and symbiotic gut microbes of herbivores enable them to retain such fibrous foods for a longer time period and to carry out adequate bacterial fermentation. In herbivores, digestion is a time-dependent process (Clauss et al. 2007), and the longer the ingesta is retained in the tract, the better digestibility becomes (Stevens and Hume 1998). Mean retention time (MRT) is the most reliable single measure to evaluate the digesta passage time. Digestibility becomes higher with an increase in MRT values in ungulates (Illius and Gordon 1992; Clauss et al. 2007). A recent review by Clauss et al. (2008) also found the same positive relationship between MRT and apparent digestibility of neutral detergent fiber (NDF; largely consisting of hemicellulose, cellulose and lignin) among primates, such as 
59 lemurs (Edwards and Ullrey 1999a; Campbell et al. 2004), howler monkeys, and colobus monkeys (Edwards and Ullrey 1999b). There are two types of digestive systems in primates; caeco-colic and forestomach fermentations (Lambert 1998). Most primate species, including

63 Japanese macaques, are caeco-colic fermenters with a relatively large colon and/or enlarged caecum for extended microbial fermentation. The colobines, like nonruminant herbivorous species such as hippos, tree kangaroos and sloths, on the other hand, are forestomach fermenters having an enlarged, sacculated forestomach, which enables the animals to carry out extended microbial fermentation (Chivers 1994; Chivers and Langer 1994; Stevens and Hume 1998). In general, caeco-colic fermenting animals feed on foods with relatively digestible components, whereas forestomach fermenting animals rely on foods with high-fiber contents (Lambert 1998). Wild primates feed on various kinds of foods, reflecting seasonal and regional differences. Japanese macaques in different regions adopt different feeding strategies, and diet composition, activity budget, and home range size are affected by the differences in food availability (Nakagawa 1997; Hanya 2004;

76 Tsuji and Takatsuki 2004). For example, Japanese macaques in both 
warm-temperate evergreen forests and cool-temperate deciduous forests confront difficulties in meeting caloric and nutritional requirements during winter (Nakagawa et al. 1996). In the evergreen forest of Koshima Island, for example, the major food resource for macaques during winter is mature leaves. These leaves contain high levels of fiber and low levels of easily digestible carbohydrates (Iwamoto 1982), but nevertheless food intake is high enough to compensate for the low diet quality. In the deciduous forest of Kinkazan Island, on the other hand, macaques feed mainly on winter buds and tree barks, which also have a relatively low nutritional quality. These food items are so small that the macaques fail to increase food intake enough to offset the low diet quality.

Based on observations of feeding behavior and nutritional analysis of their foods, Nakagawa (1989) revealed that energy intake of Japanese macaques during winter was not enough to cover maintenance energy requirements. In addition to consumption of fat accumulated during autumn (Wada et al. 1975), Japanese macaques may have physiological adaptations that enable them to meet nutritional and caloric needs when they confront such bad food conditions. If macaques are capable of increasing retention time to prolong time for bacterial fermentation under a food shortage, for example, they might need less food and 
95 thus could save time and energy searching for foods. Alternatively, they might be able to improve digestive activity by increasing total gut fill in response to

97 changes in food conditions, as in some rodent species (El-Harith et al. 1976; Owl and Batzli 1998; Naya et al. 2005).

99 In this study, we simulated variable food environments that wild populations would face using captive Japanese macaques to determine the

101 effects of food type and food intake level on mean retention time (MRT), digestibility and total gut fill as an index of gut intake capacity. We predict that MRT becomes longer in response to an increase in indigestible material intake level to have enough time for fiber digestion and prevent a decrease in

105 digestibility. We also examined the prediction that total gut fill increases when

106 the macaques consume more indigestible materials as reported in rodents.

107 This study offers new insight into the relationship between feeding ecology and nutritional physiology in primates by simultaneously examining the effects of food type and intake level on MRT and digestibility. 
113 Study Subjects

We conducted this study on four individually housed adult male

116 Japanese macaques (mean $13.6 \mathrm{~kg}$ body weight; 10.5 years old) at the

117 Research Resource Station of the Primate Research Institute, Kyoto University

118 (Table I). All of the animals were born and raised in captivity. Their usual diets

119 consist of artificial pellets with moderate-level fibers, along with some fruits and

120 vegetables such as apples and sweet potatoes. We also give them a piece of

121 wood so that they can nibble the tree bark. The animals did not have any of

122 these additional food items during each experiment. We carried out the

123 experiments from January 21, 2008 to March 29, 2008.

To investigate the effect of NDF content of food on MRT and digestibility,

128 we used high-fiber (NDF 37.5\%; Oriental Yeast Co., Ltd.) and low-fiber diets

129 (NDF 13.6\%, PMI Nutrition International) (Table II). During the first experiment,

130 we gave the animals a small amount (166 g/day in dry matter (DM), or180 g/day 
131 as fed) of high-fiber pellets to study the effects on MRT and digestibility (Table III).

132 In the next experiment, we fed them a large amount (230 $\mathrm{g} \mathrm{DM}, 250 \mathrm{~g}$ as-fed) of

133 the same high-fiber pellets. In the following two experiments, we gave the

134 animals low-fiber pellets in the same amounts (Small: $169 \mathrm{~g} \mathrm{DM}, 180 \mathrm{~g}$ as-fed;

135 Large: $235 \mathrm{~g} \mathrm{DM}, 250 \mathrm{~g}$ as-fed). Thus, we set four feeding conditions:

136 High-Small, High-Large, Low-Small and Low-Large. Low-Large represents the

137 situation where high-quality food is abundant, whereas High-Small reflects the

138 worst case scenario that macaques in deciduous forests would face during

139 winter. Daily dry matter intake (DMI) of High-Small was $166 \mathrm{~g}$ and the daily

140 energy intake was $531 \mathrm{kcal}$ (physiological fuel value; provided by the

141 manufacturer).

143 Feeding Trials

set a 3-day introduction period and a 5-day adaptation period. The first 3 days were to gradually change their diets from the original to the experimental ones.

148 During the next 5 days, the animals consumed only experimental diets so that 
149 we could exclude possible effects of the original diets they had previously had,

150 although gut microbes may take more than 8 days to adapt to the experimental

151 diet. We fed the animals twice a day, at 10:00h and at 15:00h, and quantified

152 the amount of food at the individual level. The animals consumed all of the

153 food given and water was available ad libitum. We checked body weight of the

154 animals before and after each experiment to maintain their good health (Table 155 IV).

156

157 Measurement of Digesta Passage

158

We used chromium mordanted onto cell-wall constituents (Cr-CWC;

160

$0.08 \mathrm{~g} / \mathrm{BW} \mathrm{kg}$ ) prepared from alfalfa (Medicago sativa) as the particle $\mathrm{Cr}$ marker and Cobalt-ethylene diaminetetraacetic acid (Co-EDTA; $0.04 \mathrm{~g} / \mathrm{BW} \mathrm{kg}$ ) as the fluid Co marker (Udén et al. 1980; Caton et al. 1999). We mixed the marker dose into a piece of pancake and gave it to the animals at 8:00 on Day 1 of each trial before their morning meals. 
167 the animals every 2 hours for the first 12 hours, then every 4 hours for the next 12 hours (Day 1 - Day 2). We observed the animals every 6 hours for the next 24 hours (Day 2 - Day 3) and every 8 hours for the last 72 hours (Day 3 - Day 6)

170 (Sakaguchi et al. 1991). After collecting samples, we deep-froze them

171 immediately at $-30^{\circ} \mathrm{C}$, and then vacuum-dried them at $60^{\circ} \mathrm{C}$ until reaching a constant weight. Next, we ground dried samples and stored them in plastic

173 tubes. For determination of chromium (Cr) and cobalt (Co), we ashed each fecal sample at $550^{\circ} \mathrm{C}$ for 6 hours in a muffle furnace. Then we dissolved the ashed samples in $0.1 \mathrm{~N}$ hydrochloric acid solution. We determined $\mathrm{Cr}$ and $\mathrm{Co}$ concentration in the treated sample by atomic absorption spectroscopy (Atomic absorption spectrophotometer AA-660, Shimadzu, Kyoto). Measurement of Digestibility We determined apparent digestibility of DM (aD DM) and NDF (aD NDF)

182 in each trial. To carry out nutritional analysis for each feeding trial, we pooled all the feces of the last 96 hours, from 8:00h on Day 2 to 8:00h on Day 6, for each animal (Table III). We did not use feces collected prior to this period as an 
185 precaution in addition to the 5-day adaptation period since the marker analysis suggested that complete marker excretion may take over 100 hours. same period. Since we finished the experiment before AM meal on Day 6, we

189 considered the total food intake of each trial as the sum of food given from Day 2

190 to Day 5. We determined aD NDF in duplicate from $0.5 \mathrm{~g}$ samples using the 191 methods of Van Soest et al. (1991). After removing crude fat from samples by

192 the Soxhlet method with a diethyl-ether extract, we boiled them in an NDF solution for 1 hour. We dried the NDF residues and then calculated NDF by subtracting the ashed residues from them.

Data Analysis to the formula of Blaxter et al. (1956):

$$
\operatorname{MRT}(h)=\frac{\sum_{i=1}^{N} M i T i}{\sum_{i=1}^{N} M i},
$$


203 total number of defecations. We regarded $T_{i}$ as the middle of the sampling

204 interval so that the calculated MRT would become a better indication of the true

205 MRT without frequent sampling (Van Weyenberg et al. 2006).

$$
a D(\%)=\frac{\text { Amount consumed }- \text { Fecal excretion }}{\text { Amount Consumed }} \times 100
$$

,based on an average daily food intake and excretion over 4 days.

following formula:

where $A$ is the fractional digestibility of the diet.

1989):

$$
V=V_{N}+\frac{V_{N} \cdot A}{2(1-A)}
$$

where $V_{N}$ is the indigestible material fill. Of the two formulae provided by 
221 that absorption of ingested food would occur linearly with time. We did not take

222 the fluid Co marker MRT into account since the marker used in this calculation

223 must be representative of solid ingesta (Holleman and White 1989).

224

We analyzed MRT values and digestibility using a generalized linear

225 model (GLM), where food type and intake level were independent variables

226 (food type: High = 0, Low = 1; food intake level: Large = 0, Small = 1), in R for

227 Windows version 2.9.2 (2009 The R Foundation for Statistical Computing). We

228 selected the function with the minimum Akaike Information Criterion (AIC) as the

229 best-fitted model for each feeding trial. We also analyzed the relationship

230 between MRT and digestibility as well as that between indigestible DMI and

231 MRT.

232

233 Results

high-fiber diets (Fig. 1). The best-fit model selected for the particle Cr included 
239 only food type $\left(\mathrm{Cr} M R T=12.425^{*}\right.$ food type $+35.125, \mathrm{AIC}=110.37, \mathrm{df}=15, \mathrm{~F}=$

$24013.553, P=0.002)$. Although the best-fit model for the fluid Co included both

241 food type and food intake level (Co MRT $=16.038$ * food type +5.613 * food

242 intake level $+26.456, \mathrm{AIC}=114.77, \mathrm{df}=15, \mathrm{~F}=10.131, P=0.002)$, a model

243 including only food type also had a small AIC (Co MRT $=16.038$ * food type +

$24429.262, \mathrm{AIC}=115.28, \mathrm{df}=15, \mathrm{~F}=16.614, P=0.001)$, suggesting that food type

245 had a stronger effect on the MRT of the fluid Co markers. The differences in

246 MRT for the two diet types were 12 hours for the particle $\mathrm{Cr}$ marker (high-fiber:

$24735.1 \pm 1.9 \mathrm{~h}$, low-fiber: $47.5 \pm 9.3 \mathrm{~h}$; mean \pm SD) and 16 hours in the fluid Co

248 marker (high-fiber: $29.3 \pm 3.3 \mathrm{~h}$, low-fiber: $45.3 \pm 10.6 \mathrm{~h}$ ). The amount of food

249 intake level had no effect on MRT of the both markers.

250

The amount of indigestible material in the four diets was largest in

251 High-Large, then High-Small, Low-Large, and Low-Small (Fig. 2, Table IV).

252 MRT of both markers became shorter with increasing indigestible DMI

253 (Pearson's correlation, $\mathrm{Cr}: r=-0.748, \mathrm{df}=14, P<0.001, \mathrm{Co}: r=-0.819, \mathrm{df}=14$,

$254 P<0.001$, Fig. 3), although this relation was not very clear in the high-fiber diets,

255 where the animals consumed a relatively large amount of indigestible materials. 
Digestibility

259 than those of low-fiber diets. The best-fit model selected for aD DM included only food type $(\mathrm{aD} D M=26.297$ * food type $+56.897, \mathrm{AIC}=72.50, \mathrm{df}=15, \mathrm{~F}=$ 640.73, $P<0.0001)$. Both food type and food intake level showed effects on $\mathrm{aD}$ NDF $\left(\mathrm{aD}\right.$ NDF $=11.469{ }^{*}$ food type $-4.601{ }^{*}$ food intake level $+54.746, \mathrm{AIC}$ $=100.38, \mathrm{df}=15, \mathrm{~F}=13.199, P<0.001)$, although food type appeared to be more influential than food intake level $(\mathrm{aD} N \mathrm{NDF}=11.469$ * food type +54.746 , $\mathrm{AIC}=102.34, \mathrm{df}=15, \mathrm{~F}=19.234, P<0.001 ; \mathrm{aD} \mathrm{NDF}=-4.601$ * food intake level $+60.48, \mathrm{AIC}=114.56, \mathrm{df}=15, \mathrm{~F}=1.4065, P=0.255) . \quad$ High-fiber diets had more than $25 \%$ lower aD DM compared to low-fiber diets $(56.9 \pm 1.9 \%$ and 83.2 $\pm 2.3 \%$, mean $\pm \mathrm{SD}$, respectively), and aD NDF of high-fiber diets was also lower than that of low-fiber diets $(53.6 \pm 4.4 \%$ and $62.9 \pm 9.0 \%$, respectively; Table IV). MRT and aD DM were correlated with each other in the trials with

271 low-fiber diets, but not in those with high-fiber diets (Fig. 4). Since food intake did not have an influence on MRT values, we pooled all data from the four trials and then divided them into two groups based on food type. As a result, we

274 found a significant correlation between the particle Cr MRT and aD DM in the 
275 low-fiber diet trials (Pearson's correlation, $\mathrm{Cr}: r=0.722, \mathrm{df}=6, P=0.043$ ),

276 although the slope of the regression was not steep. There was no such

277 significant correlation between the fluid Co MRT and aD DM (Co: $r=0.695$, df $=$

$2786, P=0.056)$. MRT was not correlated with either aD DM of high-fiber diets

279 (Pearson's correlation, $\mathrm{Cr}: r=-0.124, \mathrm{df}=6, P=0.769, \mathrm{Co}: r=0.432, \mathrm{df}=6, P=$ $2800.286)$ or aD NDF of both high-fiber (Cr: $r=0.285, \mathrm{df}=6, P=0.494, \mathrm{Co}: r=$

$2810.385, \mathrm{df}=6, P=0.346)$ and low-fiber $(\mathrm{Cr}: r=-0.036, \mathrm{df}=6, P=0.933, \mathrm{Co}: r=-$ $282 \quad 0.084, \mathrm{df}=6, P=0.843)$ diets.

284 Total Gut Fill

Total gut fill was associated with both food type and intake level. The

287 best-fit model for total gut fill included both food type and intake level (Total gut

288 fill $=-67.309$ * food type $-28.031^{*}$ food intake level $+142.044, \mathrm{AIC}=128.30, \mathrm{df}$

$289=15, \mathrm{~F}=80.111, P<0.0001)$. Total gut fill became greater when the animal fed

290 the diets with either larger amounts or higher fiber levels (Fig. 5).

\section{Discussion}


295 NDF rather than acid detergent fiber (ADF) as a parameter of fiber content.

296 ADF permits more precise comparisons because NDF contains partially

297 digestible hemicellulose. When two diets given to gorillas contained similar

298 levels of NDF, the one with high ADF content showed a low digestibility (Remis

299 and Dierenfeld 2004). However, the high-fiber pellets are also likely to be high

300 in ADF due to the large difference in NDF levels of the two diets we used $(37.5 \%$

301 in high-fiber; $13.6 \%$ in low-fiber, respectively). Second, we had no information

302 on NDF composition. Hemicellulose is more digestible and lignin is less

303 digestible, so the higher aD NDF of the low-fiber diet might suggest a high

304 hemicellulose content, whereas the high-fiber diet contains more lignin. Such

305 differences in NDF composition may affect aD DM of the two diets. However,

306 even if that was the case, our result would not be very different because of

307 distinct differences in both the NDF content and aD DM of the two diets. 
become much shorter when the Japanese macaques feed in the high-fiber diets.

313 This tendency has been reported for other primate species including langurs

314 (Nijboer et al. 2007) and chimpanzees (Milton and Demment 1988), and is likely

315 to e because high-fiber diets contain more indigestible materials, which push the 316 digesta out to the gut, and thus shorten the MRT. Both the apparent digestibility of dry matter and NDF (aD DM, aD NDF, respectively) depended on food type. A higher aD DM in the low-fiber diets is consistent with the previous studies on lemurs (Edwards and Ullrey 1999a), gorillas (Remis and Dierenfeld 2004), orangutans (Schmidt et al. 2009), and

321 howler and colobus monkeys (Edwards and Ullrey 1999b), and the same negative correlation exists between aD NDF and fiber contents of diets (Schmidt et al. 2009). Since high-fiber foods contain more indigestible material that inhibits absorption of nutrients, it is reasonable to find a lower $\mathrm{aD} \mathrm{DM}$ and $\mathrm{aD}$ NDF. total gut fill in the High-Small diet compared to the Low-Large diet implies a more significant effect of food type than food intake. The differences in total gut fill 
329 among the four diets may indicate the feeding strategy of Japanese macaques in

330 different food environments. When food contains a lot of fiber, the macaques

331 can meet their energy requirement either by increasing food intake level or decreasing MRT down to a point where digestibility might be compromised (Fig.

3). Once their MRT bottoms out due to high indigestible DMI, the macaques can react by increasing total gut fill in order to prevent further drops in MRT.

Effect of Food Intake Level DMI had little effect on both MRT and digestibility in Japanese macaques.

This result differs from previous studies on herbivores, where MRT became shorter as DMI increased (Fryxell et al. 1994; Clauss et al. 2004; Clauss et al. 2007), and primates, where a review of studies on 19 species found a significant negative correlation between MRT and DMI (Clauss et al. 2008). This difference in results may be due to a difference in the range of food intake levels,

344 which is expressed as relative DMI $\left(\mathrm{g} / \mathrm{kg}^{0.75} / \mathrm{d}\right)$. Relative DMI in this study is $10.2-21.0 \mathrm{~g} / \mathrm{kg}^{0.75} / \mathrm{d}$ (Table IV), which is smaller than the $11-118 \mathrm{~g} / \mathrm{kg}^{0.75} / \mathrm{d}$ range of the previous study (Clauss et al. 2008). However, the food intake level 
347 of wild Japanese macaques usually does not range that wide, and the relatively small range in food intake level (190 - 299 DM g/d over a 6-month period) among

349 macaques in the evergreen forest of Koshima (Iwamoto 1982) suggests that the food intake level in our experiment was reasonable. Indigestible DMI affected the particle Cr marker MRT while food intake level had little effect on MRT. The more the animals ingested indigestible materials, the shorter the particle Cr MRT became, although this tendency was very weak in high-fiber diets since MRT becomes more or less constant once indigestible DMI reaches a certain level (5 g/kg ${ }^{0.75} / \mathrm{d}$, approximately) (Fig. 3). The variation in the particle Cr MRT among the four diets (High-Large, High-Small, Low-Large, and Low-Small) does not seem to be as great as that found in indigestible DMI, since there is little difference in MRT between High-Large and High-Small diets (Fig. 1). This may indicate that the amount of indigestible material in High-Small is high enough to bring MRT close to the minimum level, where additional indigestible material in High-Large would no longer affect MRT. DMI was associated with total gut fill of Japanese macaques. 
365 Low-Large diet showd greater total gut intake than Low-Small diet (Fig. 5).

366 Japanese macaques may be capable of increasing DMI by increasing total gut

367 fill when they need to consume a large amount of food. Based on the

combined effects of both food type and intake level on total gut fill, we conclude

369 that Japanese macaques have a flexible digestive tract that enables them to deal with different food conditions. diets become higher when MRT is longer. However, the correlation was small since the range of $\mathrm{aD} \mathrm{DM}(79.4-85.6 \%)$ was much smaller than that of MRT aD DM was improved by increased MRT. Compared to low-fiber diets, high-fiber diets showed a much smaller range of MRT (Cr: 32.6 - $38.6 \mathrm{~h}$; Co: $24.6-34.2 \mathrm{~h}$ ), so we could not examine the influence of MRT on aD DM in the high-fiber diets. 
383 fermentation of structural carbohydrates requires time. This is true for

384 leaf-eating primates such as the colobines (Edwards and Ullrey 1999b; Nijboer

385 et al. 2007), but not for Japanese macaque since they have a shorter MRT and

386 lower aD DM in the high-fiber diets. Our results indicate that the macaques

387 have a flexible digestive system that allows them to deal with various food

388 conditions and that there seems to be a gut capacity threshold around $5 \mathrm{~g}$

389 indigestible $\mathrm{DMI} / \mathrm{kg}^{0.75} / \mathrm{d}$. Below this threshold, the more indigestible materials

390 the macaques ingest, the shorter MRT becomes. Once they reach the

391 threshold by consuming high-fiber foods or a relatively large amount of low-fiber

392 foods, their gut simply expands. These findings suggest that Japanese

393 macaques ensure MRT never becomes too short; not less than $30 \mathrm{~h}$ for particles.

394 Some rodent species are also known to have a flexible digestive strategy to

395 meet their energy requirements, increasing the size of the digestive tract in

396 response to temperature (Naya et al. 2005) or diet types (El-Harith et al. 1976;

397 Owl and Batzli 1998; Naya et al. 2005), suggesting better digestion due to

398 increased fermentative activity.

400 Implications for the Feeding Ecology of Wild Japanese Macaques 
403 processing strategies in different food environments. When low-fiber food is available and indigestible DMI range is low, macaques excrete difficult-to-digest

405 foods quickly so that they can increase their food intake level. When food contains a lot of fiber, they can meet their energy requirement either by

407 increasing food intake level or developing a greater total gut fill. which are low in energy content (Iwamoto 1982). However, since leaves are large in size, they can stuff themselves with such food in a short feeding time.

411 In such a food environment, the macaques may meet their energy requirements by increasing food intake level and/or by developing a greater gut fill. In winter

413 deciduous forests, on the other hand, few mature leaves are available and macaques eat mainly winter buds and tree barks, which reduce intake rate and are difficult to digest (Nakagawa 1989). These animals must therefore survive

416 even severer food conditions. Macaques in deciduous forests lose their body weight in winter by consuming fat deposited during autumn (Wada 1975; Wada et al. 1975; Koganezawa 1995). One possible way to deal with such a situation 
419 is to increase gut capacity so that they can retain indigestible materials in the gut

420 long enough to maintain fiber digestibility. Having an almost constant particle

421 MRT in the high indigestible DMI range may imply such an ability. The fact that

422 the fecal microflora of wild Japanese macaques in a snowy district was different

423 from that of captive ones (Benno et al. 1987) might also imply that wild Japanese macaques have another digestive function de to unique intestinal microflora Thus, our finding might not fully explain feeding adaptations in wild Japanese macaques and further study of wild macaques is required. than that of low-fiber food regardless of food intake level. Our findings suggest that Japanese macaques are capable of dealing with various food conditions by

431 adopting different food processing strategies, under the strong influence of

432 indigestible DMI level. Macaques excrete difficult-to-digest materials quickly in 433 the low indigestible DMI range, while they have a constant MRT once

434 indigestible DMI exceeds a threshold. These results demonstrate the need to take food type or indigestible DMI into account when comparing MRT and digestibility within or among primate species. 


\section{Acknowledgements}

the Center for Human Evolution Modeling Research, Primate Research Institute,

443 Kyoto University (KUPRI), and Kiyonori Kumazaki and Naoko Suda of the

444 Research Resource Station, KUPRI for their great support in carrying out the

445 experiments. We are also thankful for the help of the members of the

446 Laboratory of Animal Nutrition, Okayama University, in marker analysis. We

447 appreciate Dr. Marcus Clauss, anonymous reviewer and the editor of this journal

448 as well as the staff of KUPRI giving us helpful comments and advice on this

449 study. Our study complied with the guidelines in KUPRI 's "Guide for the Care

and Use of Laboratory Primates". This research has been approved by the

451 ethics committee of KUPRI and financially supported in part by the Global

452 Center of Excellence Program "Formation of a Strategic Base for Biodiversity and Evolutionary Research: from Genome to Ecosystem" of the Ministry of

454 Education, Culture, Sports and Technology (MEXT), Japan. 


\section{References}

Blaxter, K. L., MacGraham, N. M., \& Wainman, F. W. (1956). Some observations on the digestibility of food by sheep and on related problems. British Journal of Nutrition, 10(2), 69-91.

Benno, Y., Itoh, K., Miyao, Y., \& Titsuoka, T. (1987). Comparison of fecal microflora between wild Japanese monkeys in a snowy area and laboratory-reared Japanese monkeys. Japanese Journal of Veterinary Science, 49(6), 1059-1064.

Campbell, J. L., Williams, C. V., \& Eisemann, J. H. (2004). Use of total dietary fiber across four lemur species (Propithecus verreauxi coquereli, Hapalemur griseus griseus, Varecia variegata, and Eulemur fulvus): Does fiber type affect digestive efficiency? American Journal of Primatology, 64, 323-335.

Caton, J. M., Hume, I. D., Hill, D. M., \& Harper, P. (1999). Digesta retention in the gastro-intestinal tract of the orang utan (Pongo pygmaeus). Primates, 40(4), 551-558.

Chivers, D. J. (1994). Functional anatomy of the gastrointestinal tract. In A. G. Davies \& J. F. Oates (Eds.), Colobine monkeys: Their Ecology, Behaviour and Evolution (pp. 205-227). Cambridge: Cambridge University Press.

Chivers, D. J., \& Langer, P. (Eds.). (1994). The digestive system in mammals: Food, form and function. Cambridge: Cambridge University Press.

Clauss, M., Streich, W. J., Schwarm, A., Ortmann, S., \& Hummel, J. (2007). The relationship of food intake and ingesta passage predicts feeding ecology in two different megaherbivore groups. Oikos, 116(2), 209-216.

Clauss, M., Streich, W. J. g., Nunn, C. L., Ortmann, S., Hohmann, G., Schwarm, A., et al. (2008). The influence of natural diet composition, food intake level, and body size on ingesta passage in primates. Comparative Biochemistry and Physiology - Part A: Molecular \& Integrative Physiology, 150(3), 274-281.

Clauss, M., Schwarm, A., Ortmann, S., Alber, D., Flach, E. J., Kühne, R., et al. (2004). Intake, ingesta retention, particle size distribution and digestibility in the hippopotamidae. Comparative Biochemistry and Physiology - Part A: Molecular \& Integrative Physiology, 139(4), 449-459.

Edwards, M. S., \& Ullrey, D. E. (1999a). Effect of dietary fiber concentration on apparent digestibility and digesta passage in non-human primates. I. 
Ruffed lemurs (Varecia variegata variegata and V. v. rubra). Zoo Biology, 18(6), 529-536.

Edwards, M. S., \& Ullrey, D. E. (1999b). Effect of dietary fiber concentration on apparent digestibility and digesta passage in non-human primates. II. Hindgut- and foregut-fermenting folivores. Zoo Biology, 18(6), 537-549.

El-Harith, E. A., Dickerson, J. W. T., \& Walker, R. (1976). Potato starch and caecal hypertrophy in the rat. Food and Cosmetics Toxicology, 14(2), 115-121.

Fryxell, J. M., Vamosi, S. M., Walton, R. A., \& Doucet, C. M. (1994). Retention time and the functional response of beavers. Oikos, 71(2), 207-214.

Hanya, G. (2004). Seasonal variations in the activity budget of Japanese macaques in the coniferous forest of Yakushima: Effects of food and temperature. American Journal of Primatology, 63(3), 165-177.

Holleman, D. F., \& White, R. G. (1989). Determination of digesta fill and passage rate from nonabsorbed particulate phase markers using the single dosing method. Canadian Journal of Zoology, 67(2), 488-494.

Illius, A. W., \& Gordon, I. J. (1992). Modelling the nutritional ecology of ungulate herbivores: evolution of body size and competitive interactions. Oecologia, 89(3), 428-434.

Iwamoto, T. (1982). Food and nutritional condition of free ranging Japanese monkeys on Koshima Islet during winter. Primates, 23(2), 153-170.

Koganezawa, M. (1995). Body fat indices and their seasonal variations in Japanese monkeys of Nikko, Japan (in Japanese with English abstract). Wildlife Conservation Japan, 1(1), 31-36.

Lambert, J. E. (1998). Primate digestion: Interactions among anatomy, physiology, and feeding ecology. Evolutionary Anthropology: Issues, News, and Reviews, 7(1), 8-20.

Milton, K., \& Demment, M. W. (1988). Digestion and passage kinetics of chimpanzees fed high and low fiber diets and comparison with human data. Journal of Nutrition, 118(9), 1082-1088.

Nakagawa, N. (1989). Bioenergetics of Japanese monkeys (Macaca fuscata) on Kinkazan Island during winter. Primates, 30(4), 441-460.

Nakagawa, N. (1997). Determinants of the dramatic seasonal changes in the intake of energy and protein by Japanese monkeys in a cool temperate forest. American Journal of Primatology, 41(4), 267-288.

Nakagawa, N., Iwamoto, T., Yokota, N., \& Soumah, A. G. (1996). Inter-regional 
and inter-seasonal variations of food quality in Japanese macaques: constraints of digestive volume and feeding time. In J. E. Fa \& D. G. Lindburg (Eds.), Evolution and ecology of macaque societies. Cambridge: Cambridge University Press.

Naya, D. E., Bacigalupe, L. D., Bustamante, D. M., \& Bozinovic, F. (2005). Dynamic digestive responses to increased energy demands in the leaf-eared mouse ( Phyllotis darwini). Journal of Comparative Physiology B: Biochemical, Systemic, and Environmental Physiology, 175(1), 31-36.

Nijboer, J., Clauss, M., Van de Put, K., Van der Kuilen, J., Woutersee, H., \& Beynen, A. C. (2007). Influence of two different diets on fluid and particle retention time Javan langur (Trachypithecus auratus auratus). Der Zoologische Garten, 77(1), 36-46.

Owl, M. Y., \& Batzli, G. O. (1998). The integrated processing response of voles to fibre content of natural diets. Functional Ecology, 12(1), 4-13.

Remis, M., \& Dierenfeld, E. (2004). Digesta passage, digestibility and behavior in captive gorillas under two dietary regimens. International Journal of Primatology, 25(4), 825-845.

Robbins, C. T. (1983). Wildlife feeding and nutrition. New York: Academic Press.

Sakaguchi, E., Suzuki, K., Kotera, S., \& Ehara, A. (1991). Fiber digestion and digesta retention time in macaque and colobus monkeys. In A. Ehara, T. Kumura, O. Takenaka \& M. Iwamoto (Eds.), Primatology Today: Proceedings of XIIIth Congress of the International Primatological Society New York: Elsevier Science Publishers B. V.

Schmidt, D. A., Kerley, M. S., Dempsey, J. L., Porton, I. J., Porter, J. H., Griffin, M. E., et al. (2009). Fiber digestibility by the orangutan (Pongo abelii): In vitro and in vivo. Journal of Zoo and Wildlife Medicine, 36(4), 571-580.

Stevens, C. E., \& Hume, I. D. (1998). Contributions of microbes in vertebrate gastrointestinal tract to production and conservation of nutrients. Physiological Reviews, 78(2), 393-427.

Tsuji, Y., \& Takatsuki, S. (2004). Food habits and home range use of Japanese macaques on an island inhabited by deer. Ecological Research, 19(4), 381-388.

Udén, P., Colucci, P. E., \& van Soest, P. J. (1980). Investigation of chromium, cerium and cobalt as markers in digesta. Rate of passage studies. Journal of the Science of Food and Agriculture, 31(7), 625-632.

Van Weyenberg, S., Sales, J., \& Janssens, G. P. J. (2006). Passage rate of 
563

564

565

566

567

568

569

570

571

572

573

digesta through the equine gastrointestinal tract: A review. Livestock Science, 99(1), 3-12.

Wada, K. (1975). Ecology of wintering among Japanese monkeys in Shiga heights and its adaptive significance (in Japanese with English abstract). Physiology and Ecology, 19, 9-14.

Wada, K., Moritani, K., Hara, F., \& Ohsawa, W. (1975). On the body fat of Japanese monkeys inhabiting the Shiga Heights (in Japanese with English abstract). Physiology and Ecology, 16(1), 104-107. 
574

575

576

577

578

579

580

581

582

583

584

585

586

587

588

589

590

\section{Figure legends}

Fig. 1 Mean retention time (MRT; h) of two markers by Japanese macaques among four feeding conditions. Box indicates upper and lower quartiles; horizontal line indicates the median; whiskers indicate the range.

Fig. 2 Indigestible DMI in four feeding conditions.

Fig. 3 The relationship between indigestible DMI and particle Cr MRT.

Fig. 4 Relationships between MRT of the markers and apparent digestibility.

(a) aD DM (b) aD NDF with the particle Cr marker MRT, (c) aD DM and (d) aD NDF with the fluid Co marker MRT.

Fig. 5 Total gut fill in four feeding conditions.

Table I. Details of the animals used in this study

\begin{tabular}{lllllll}
\hline Species & Animal & Born & Age (year) Origin & Sex & BW $(\mathrm{kg})$ \\
\hline M. fuscata 1 & 1995 & 13 & Captive & Male & 13.2 \\
M. fuscata 2 & 1995 & 13 & Captive & Male & 16.4 \\
M. fuscata 3 & 1997 & 11 & Captive & Male & 14.7 \\
M. fuscata & 4 & 1999 & 9 & Captive & Male & 11.8 \\
\hline
\end{tabular}

BW (body weight) was measured on January $20^{\text {th }}, 2008$, a day prior to the start of the first experiment. 
592 Table II. Major nutritional values of two commercial pellets and energy intake of

593 four feeding conditions

\begin{tabular}{lrr}
\hline & High-Fiber $^{*}$ & Low-Fiber $^{* *}$ \\
\hline Crude protein (\%) & 18.6 & 25.9 \\
Crude fat (\%) & 3.4 & 4.7 \\
NDF (\%) & 37.5 a & 13.6 \\
Crude ash (\%) & 12.1 & 5.7 \\
Physiological fuel value (kcal / g) & 2.95 & 3.40 \\
$\quad$ kcal / Large & 737.5 & 850.0 \\
kcal / Small & 531.0 & 612.0 \\
\hline
\end{tabular}

$595 \quad$ All values are expressed on a fresh basis.

596 NDF (neutral detergent fiber) $=$ hemicellulose, cellulose and lignin

597 Physiological fuel value $(\mathrm{kcal} / \mathrm{g})=$ Sum of decimal fractions of proteins, fat and carbohydrate x 4, 9, $4 \mathrm{kcal} / \mathrm{g}$, respectively

* Diet for Zoo Animal (ZF), Oriental Yeast Co. Ltd, Tokyo

600

** Certified Primate Diet, PMI Nutrition International, Montana

601

a Data from Sakaguchi et al. (1999)

602

603 Table III. Mean \pm SD food intake and feces excretion for each feeding trial

\begin{tabular}{lrllll}
\hline & \multicolumn{2}{c}{ Food intake } & & \multicolumn{2}{c}{ Feces excretion } \\
\cline { 2 - 3 } \cline { 5 - 6 } Diet & \multicolumn{1}{c}{ As fed $(\mathrm{g})$} & DM $(\mathrm{g})$ & & DM $(\mathrm{g})$ & Frequency \\
\hline High-Large & $1002.8 \pm 2.3$ & $921.5 \pm 2.2$ & & $400.2 \pm 14.6$ & $14.0 \pm 0.0$ \\
High-Small & $723.3 \pm 0.1$ & $664.7 \pm 0.1$ & & $284.2 \pm 15.5$ & $11.8 \pm 1.5$ \\
Low-Large & $1004.7 \pm 0.6$ & $940.0 \pm 0.6$ & & $155.4 \pm 20.7$ & $10.3 \pm 1.5$ \\
Low-Small & $722.9 \pm 0.2$ & $676.3 \pm 0.2$ & & $117.7 \pm 16.1$ & $9.0 \pm 1.4$ \\
\hline
\end{tabular}

604

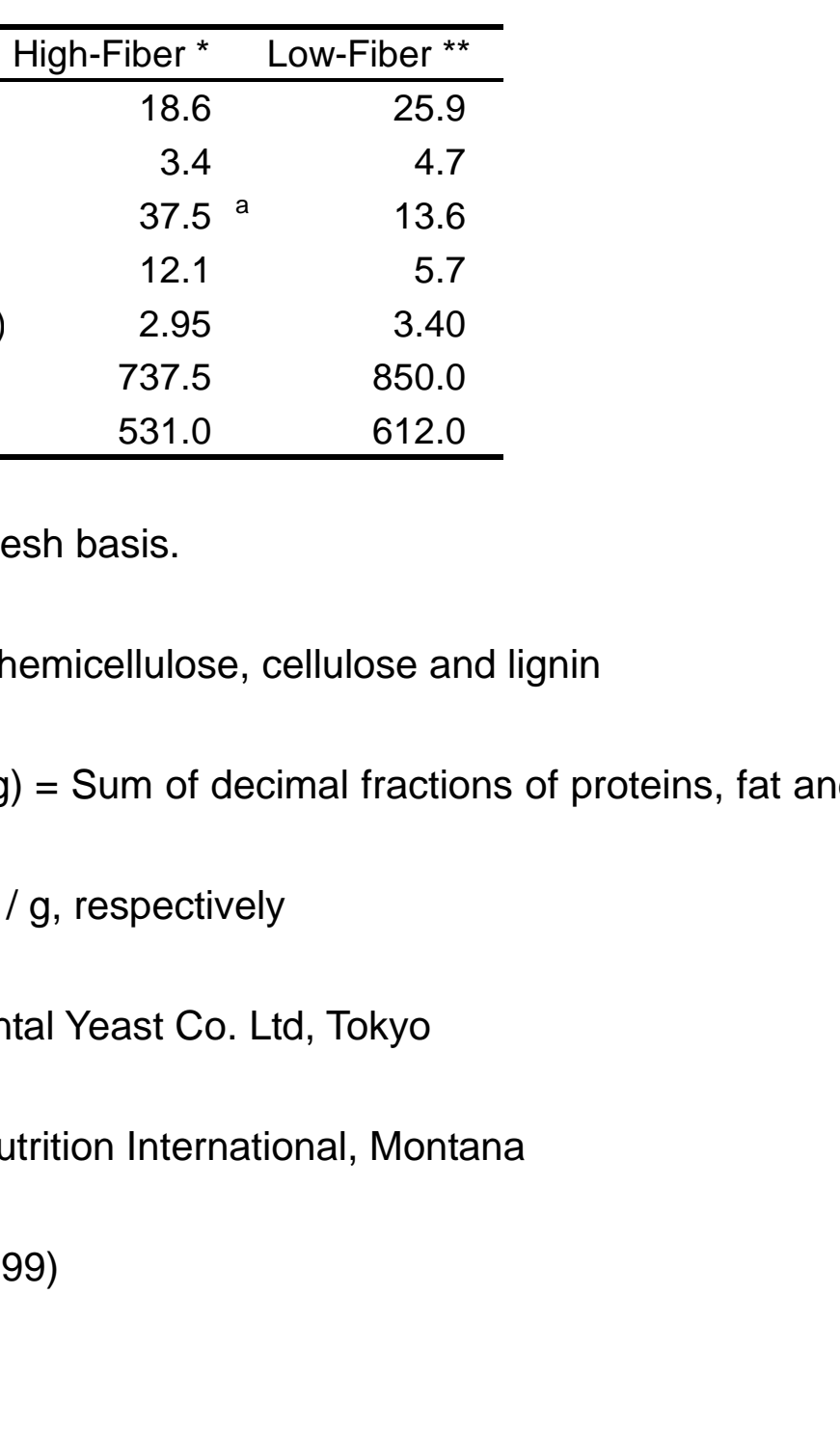


605 Food intake is expressed both in fresh (As fed) and dry matter (DM).

606 Frequency indicates the number of times that we collected fecal samples out of

60714 collection times. All values are measured over 96 hours excluding first 24

608 hours.

609 High-Large $=$ high-fiber diet in a large amount; High-Small = high-fiber diet in a

610 small amount; Low-Large = low-fiber diet in large amount; Low-Small = low-fiber 611 diet in small amount 
612 Table IV. Food and indigestible intake, MRT, digestibility and body weight of the animals under four feeding conditions

\begin{tabular}{|c|c|c|c|c|c|c|c|c|c|c|c|}
\hline \multirow[b]{2}{*}{ Diet } & \multirow[b]{2}{*}{ Animal } & \multicolumn{2}{|c|}{ BW } & \multicolumn{2}{|c|}{ DMI } & \multicolumn{2}{|c|}{ indigestible DMI } & \multicolumn{2}{|c|}{ MRT } & \multicolumn{2}{|c|}{$\mathrm{aD}$} \\
\hline & & Initial $(\mathrm{kg})$ & Final $(\mathrm{kg})$ & (g/day) & $\left(\mathrm{g} / \mathrm{kg}^{0.75} / \mathrm{day}\right)$ & (g/day) & $\left(\mathrm{g} / \mathrm{kg}^{0.75} /\right.$ day $)$ & $\mathrm{Cr}(\mathrm{h})$ & Co (h) & DM (\%) & NDF (\%) \\
\hline High-Large & 1 & 13.2 & 13.0 & 230.1 & 33.2 & 96.0 & 13.9 & 35.3 & 31.9 & 58.3 & 48.2 \\
\hline & 2 & 16.4 & 16.4 & 230.3 & 28.3 & 99.0 & 12.2 & 34.4 & 26.3 & 57.0 & 55.6 \\
\hline & 3 & 14.7 & 13.5 & 230.2 & 30.7 & 104.8 & 14.0 & 37.1 & 28.4 & 54.5 & 52.7 \\
\hline & 4 & 11.8 & 10.7 & 231.2 & 36.3 & 100.4 & 15.8 & 35.2 & 24.6 & 56.6 & 55.1 \\
\hline High-Small & 1 & 13.0 & 12.6 & 166.1 & 24.3 & 70.5 & 10.3 & 34.2 & 32.5 & 57.5 & 48.9 \\
\hline & 2 & 16.3 & 15.9 & 166.1 & 20.5 & 69.7 & 8.6 & 38.6 & 34.2 & 58.0 & 55.3 \\
\hline & 3 & 14.2 & 13.7 & 166.1 & 22.7 & 67.4 & 9.2 & 32.6 & 28.8 & 59.4 & 53.6 \\
\hline & 4 & 11.6 & 11.6 & 166.1 & 26.4 & 76.6 & 12.2 & 33.6 & 27.4 & 53.9 & 50.1 \\
\hline Low-Large & 1 & 12.8 & 12.5 & 235.3 & 34.8 & 33.9 & 5.0 & 49.9 & 51.2 & 85.6 & 64.9 \\
\hline & 2 & 16.3 & 16.2 & 235.2 & 29.0 & 38.9 & 4.8 & 42.7 & 41.3 & 83.4 & 71.9 \\
\hline & 3 & 14.0 & 13.7 & 235.0 & 32.5 & 36.5 & 5.0 & 48.8 & 40.5 & 84.4 & 68.7 \\
\hline & 4 & 11.2 & 10.6 & 234.8 & 38.4 & 46.0 & 7.5 & 34.9 & 31.6 & 80.4 & 66.6 \\
\hline Low-Small & 1 & 13.0 & 12.9 & 169.1 & 24.7 & 25.2 & 3.7 & 56.0 & 55.2 & 85.1 & 52.3 \\
\hline & 2 & 16.4 & 16.6 & 169.1 & 20.7 & 26.3 & 3.2 & 53.0 & 51.0 & 84.5 & 66.9 \\
\hline & 3 & 13.5 & 14.1 & 169.1 & 24.0 & 29.3 & 4.2 & 60.2 & 59.9 & 82.7 & 65.2 \\
\hline & 4 & 10.7 & 11.1 & 169.0 & 28.6 & 34.8 & 5.9 & 34.9 & 31.7 & 79.4 & 54.9 \\
\hline
\end{tabular}

614 
617 Diet: High = high-fiber diet, Low = low-fiber diet, Large = large amount, Small =

618 small amount; Initial BW = body weight of the animals measured before each

619 feeding trial; Final BW = body weight measured after each trial; DMI = dry matter

620 intake; MRT = mean retention time of the two markers (Cr: particle, Co: fluid); aD

$621 \mathrm{DM}=$ apparent DM digestibility; aD NDF = apparent NDF digestibility 